\title{
Applied Body Scanning Technology for the Extreme Sports Apparel
}

\author{
Stacy $\mathrm{HOLT}^{\mathrm{a}}$, Yoram BURG ${ }^{\mathrm{b}}$, Rick ELDER ${ }^{\mathrm{c}}$ \\ ${ }^{a}$ Holt Consulting Ltd., Vancouver BC, Canada; \\ ${ }^{b}$ OptiTex USA, New York NY, USA; \\ ${ }^{\mathrm{c}}$ Beyond Clothing LLC, Seattle WA, USA \\ http://dx.doi.org/10.15221/13.050
}

\begin{abstract}
Whole body 3D scanning is an important tool for collecting measurement data for the custom fit apparel markets. The ability to take measurements en mass for a specific group such as the uniforms for hotels and military is quickly being adopted. Once those measurements are captured for the group, the data can be used for size prediction of standard sizes or for custom fit orders.

The challenge for custom fit centers on the product types being offered. Defining the product with target market, technical design, measurements and parametric modeling in mind will greatly increase the success of servicing the custom fit business.

Stacy Holt, an Apparel Engineer with over 25 years' experience in apparel manufacturing and product development will explore how these challenges are overcome with the use of the latest apparel CAD technologies. Optitex's PDS, Virtual Prototyping and Modulate software will be used to demonstrate the process. Beyond Clothing Ltd, a manufacturer of extreme sports and mission apparel will assist with live subjects and styles.
\end{abstract}
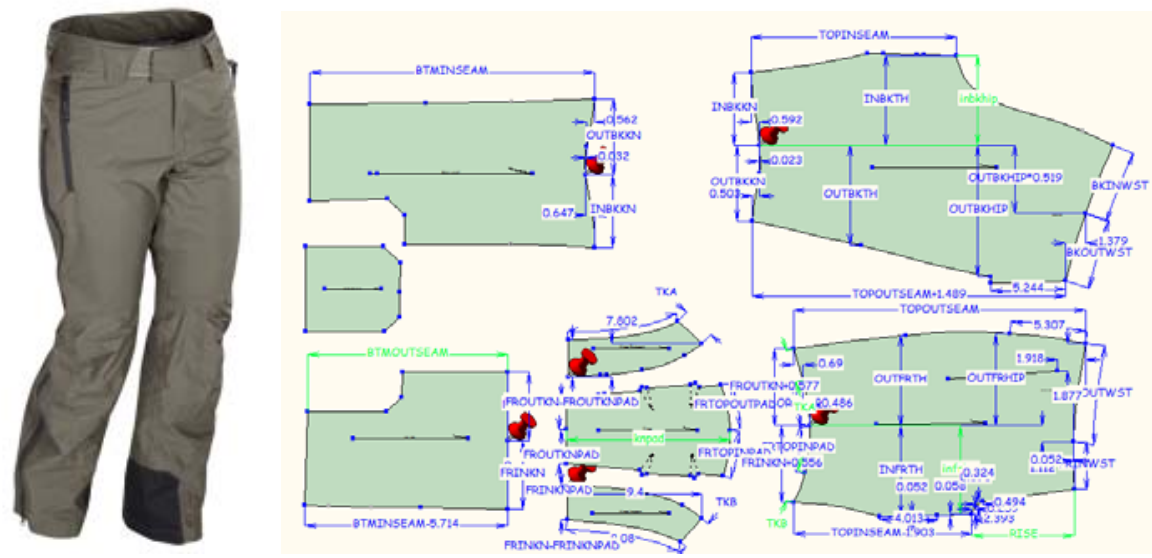

\section{Introduction}

After much deliberation and review of options in the market place, you have come to the conclusion that Custom Fit services using a whole body scanner to capture measurements would better serve your customer and ultimately your business.

But how do you get started? What measurements are important?

First lets look at how you got here:

\section{Target Market}

You have a product and a target market. How would your customer be best served with a custom fit garment? What are the inherent fit tolerances in your product?

Examples:

Mens Suits - High fitting tolerance especially in the shoulders and chest. A properly fitted suit is most noticeable in the fit in the shoulders and chest. Lengths are are important. Customer preferences are a factor. Aplicable to Uniform markets

Womens Suits and Fashion - Accommodate High Bust to Underbust proportions, Waist to Hip proportions. Lengths are a factor but not as much as in Mens. Customer preferences are factor. Applicable to uniform markets

Post Operative Garments- For burn, facial surgeries - low tolerance fit, value high need to be correct measurements. Modesty and personal esteem play a factor. Medical advice is factor. 
Performance Apparel - Health, Safety and Mobility are major factors. Protection from elements Fire, water, air, gravity. For example: Torso coverage for protective body armour, positioning of elbow and knee pads. Load carrying and access to equipment.

\section{Sizing}

Current sizing systems are designed for Mass Market consumers. Sizing systems have been fined tuned by focusing on:

- Gender - body shape, proportions and posture

- Ethnicity - body shape, proportions and posture

- Age - Weight and gravity affect body shape

- Economic Factors - How many SKUS do you want to carry?

S-M-L-XL does not serve $100 \%$ of the population even for the above market segments. Most sizing systems are based on GIRTH where the Height is proportional changed for each Girth range

When you consider that our global demographics are becoming more and more homogenous it becomes more difficult to narrow down the range of fits for a given target market.

Key Fit Factors:

- GIRTH

- HEIGHT

- BODY PROPORTIONS

- POSTURE

$\begin{array}{ll}\text { GIRTH } & \text { LENGTHS } \\ \text { CHEST } & \text { HEIGHT } \\ \text { WAIST } & \text { TORSO } \\ \text { HIP } & \text { INSEAM } \\ \text { THIGH } & \text { WAIST HEIGHT } \\ \text { NECK } & \text { SHOULDER WIDTH } \\ \text { BICEP } & \text { SLEEVE LENGTH } \\ \text { WRIST } & \end{array}$

\section{BODY PROPORTIONS}

Comparative differences

Chest to Waist

Waist to Hip

Hip to Thigh

Chest to Bicep

Chest to Neck

Analysis of these differences to body type categorizing using commonly used terms like 'hourglass', 'pear', 'apple' or ' $\mathrm{H}$ '.

$\begin{array}{lll}\begin{array}{l}\text { POSTURE } \\ \text { Lack of Muscle Tone } \\ \text { Muscle Development }\end{array} & \begin{array}{l}\text { Belly, Soft tissues } \\ \text { shoulders built out } \\ \text { Thigh and leg built out }\end{array} & \\ \text { Skeletal } & \begin{array}{l}\text { Hunchback } \\ \text { Sway back }\end{array} & \begin{array}{l}\text { shoulders rolled forward } \\ \text { profile curved back }\end{array}\end{array}$

Age is the biggest contributor to posture.

But genetics and early childhood habits can lead to differences in posture. 


\section{The Perfect Fit}

Conduct a fitting of a basic shirt with 3 designers and 3 will have a different opinion. Some of the variables that affect the intended designs outcome:

- Fabric

- Construction

- Fit Model

- Intended Ease and measurements

- Finished Lengths

- Esthetics - colour, feel, texture

- Functionality

- Compatibility with other products

Did the pattern maker and sample sewer executer the designer's original vision?

A clear definition of the designer's vision, communicated to the customer will assist in managing your customer's expectation in their custom fit garment.

\section{Focus on Extreme Sports}

What is an extreme sport? A high energy activity that includes an element of risk. The activity may need protection, gear support and/or performance enhancing from their clothing.

\section{Demographic}

Athletic with average to high levels of fitness. Body fats are average to low. Since the garments are inherently designed for high mobility, the garmenta are either designed with fabrics that have stretch or have extra functional ease.
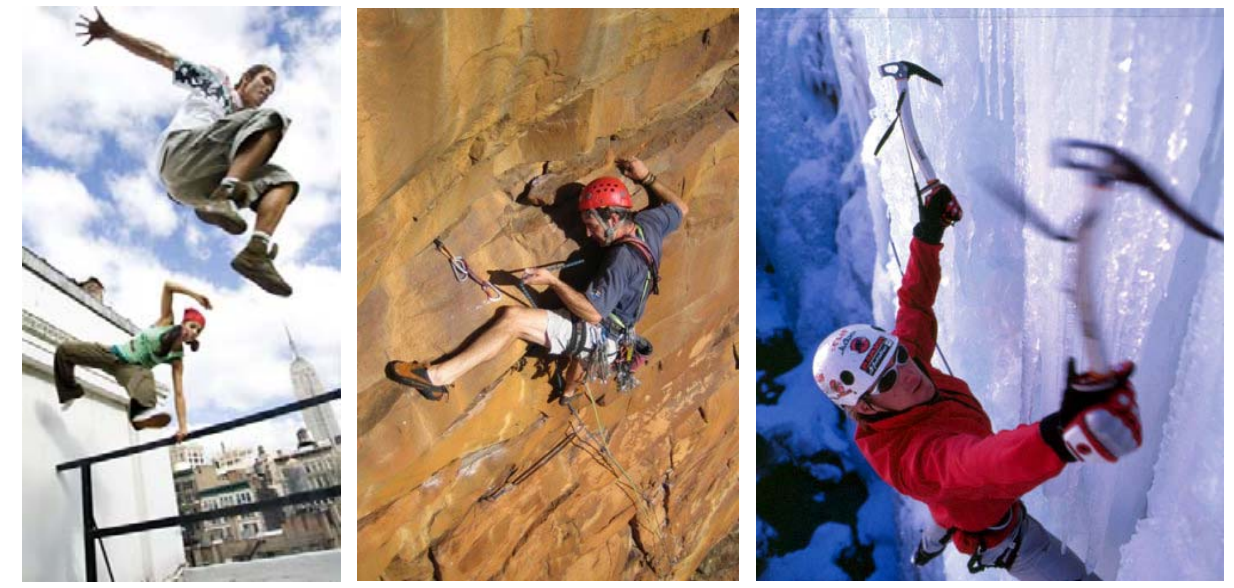

Figure 1. http://extremefreestyle.wordpress.com/2008/05/24/list-of-extreme-sports/

\section{Functional Design Elements}

- Protection from elements - fire, water, heat and cold

- Protection from hard objects and surfaces - torso, head, knees elbows, shins, etc.

- Mobility - articulated elbows, knees, crotch gussets

- Access - access to load carrying accessories - pockets, belted items, packs, harness

Positioning of support items and mobility - it is not about getting the perfect 'looking' suit!

\section{Product Development}

Once your target market and fit factors have been defined, product development can start.

1. Define your base size model measurements. This will be your average and typical customer. Your model will used to fit and test the functionality of the garment.

See Points of Measure chart on next page

2. Create your base size pattern. The pattern and technical specifications are developed. This process involves cutting and sewing your garment as per the functional design.

See example of Production Patterns on figure 3 
3. Define measurements to be extracted from whole body scans of your customer See example of view on figure 4

4. Scan the base size fit model for your base model measurements taken in the same way as your customers.

5. Define the parametric modeling for the prerequisite measurements to be extracted See example of view on figure 5

6. Test parametric model on a test group of candidates. This includes scanning all the candidates and conducting a test run. Evaluate results and adjust accordingly.

7. Ready for production orders!

\section{Points of Measure}

Define the Points of Measure that are important for the product to meet the needs of the target market.

For a performance product, the positioning of design elements and maintaining are mobility are the goal. Typical measurements to alter a product to meet the needs of different customers are Girth and Lengths. Less focus is on posture and proportions.

\begin{tabular}{|c|c|c|c|c|c|c|}
\hline & & FIT MODEL & PAN & & SHI & \\
\hline & & Body & Pattern & Ease & Pattern & Ease \\
\hline Cervical to Crotch & & 28.5 & & & 29 & 0.5 \\
\hline Cervical to Wrist & & 34 & & & 34.75 & 0.75 \\
\hline Waist to Hip & Pant Waist & 7 & 7 & 0 & & \\
\hline Waist to Crotch & Pant Waist & 11 & 11 & 0 & & \\
\hline Waist to Knee & Pant Waist & 22 & & & & \\
\hline Waist to Floor & Pant Waist & 39.25 & & & & \\
\hline Chest Circumference & & 40 & & & 44 & 4 \\
\hline Waist Circumference - Pant & Pant Waist & 34.5 & 33.5 & -1 & 42 & 7.5 \\
\hline Hip Circumference - 7" DN & $\mathrm{n}$ Nat Wst & 40.5 & 44 & 3.5 & 43 & 2.5 \\
\hline Thigh Circumference & & 25.25 & 27.5 & 2.25 & & \\
\hline Knee Circumference & & 16 & 20.5 & 4.5 & & \\
\hline Neck Circumference & & 15.5 & & & 17.5 & 2 \\
\hline Shoulder Width & & 18 & & & & \\
\hline Bicep & & 14 & & & 20.5 & 6.5 \\
\hline
\end{tabular}

Style Features to be proportionally managed

Shirt Center Front Zipper

Shirt Chest Pocket

Shirt Back Pocket

Pant Hand Pocket

Pant Fly Zipper

Pant Back Pocket

Pant Hip Pocket

Allowance from Hem to Floor

Waist to Knee
Alter proportionally to Cervical to Crotch

Alter proportionately to Chest Circumference

Alter proportionately to Chest Circumference

Alter proportionately to Hip Circumference Alter proportionately to Waist to Crotch Alter proportionately to Hip Circumference Alter proportionately to Hip Circumference Don't change

Alter Proportionately to Crotch to Floor 

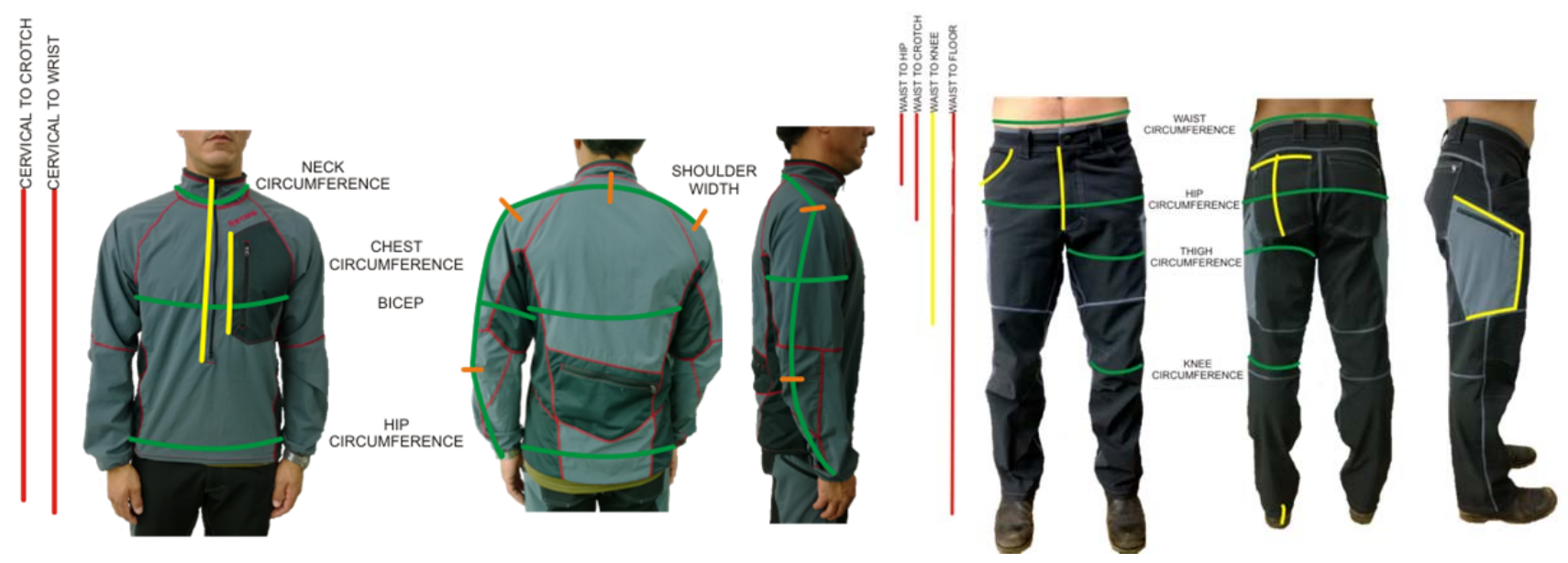

Figure 2. Points of measure
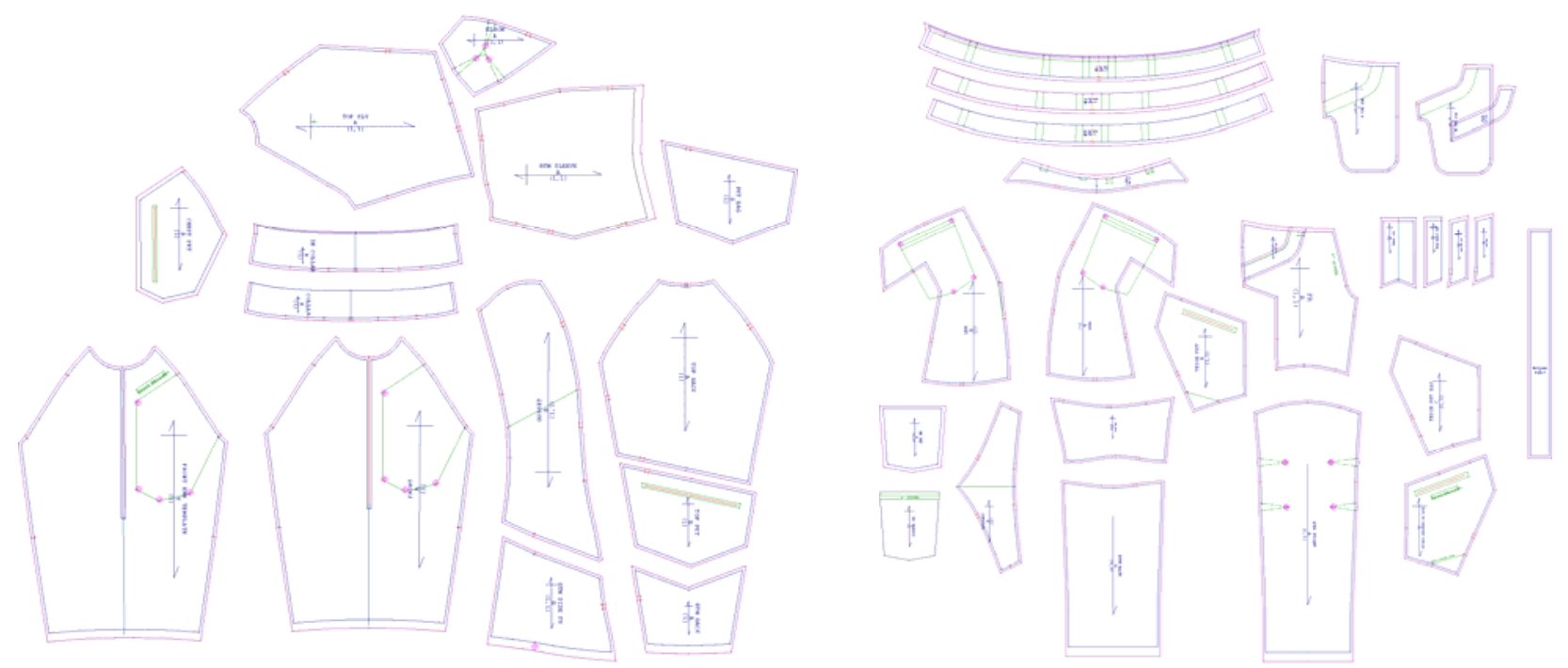

Figure 3. Production Shirt Pattern (left), Production Pant Pattern (right). Optitex PDS used for Pattern Making.
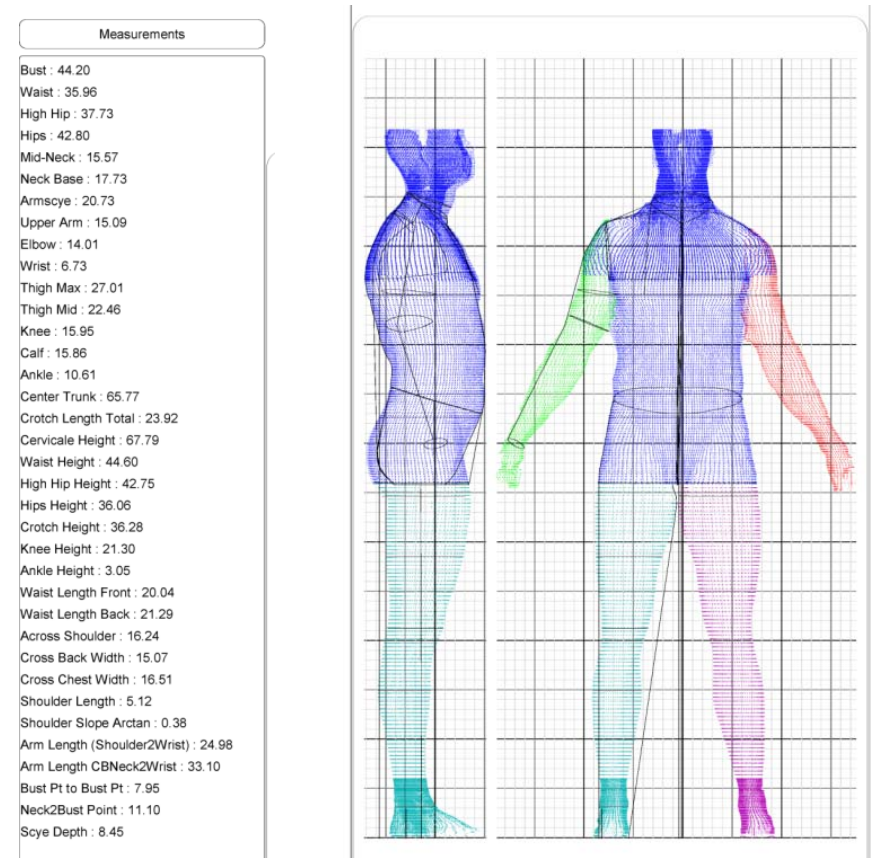

Figure 4. Example of Measurement Extraction Output. 
Named Dimensions

$\begin{array}{lr}\text { FRHIP } & 8.7 \\ \text { BKHIP } & 8.675 \\ \text { FRBUST } & 8.517 \\ \text { BKBUST } & 8.483 \\ \text { BKSHLD } & 6.806 \\ \text { CBNKtoHEM } & 22 \\ \text { sideseam } & 14.662 \\ \text { SLVLEN } & 24 \\ \text { SLVSHORT } & 7.25 \\ \text { FRNK } & 5.358 \\ \text { BKNK } & 3.855 \\ \text { UPARM } & 12.798 \\ \text { bkarm } & 8.326 \\ \quad \text { frarm } & 8.326\end{array}$

Input Variables

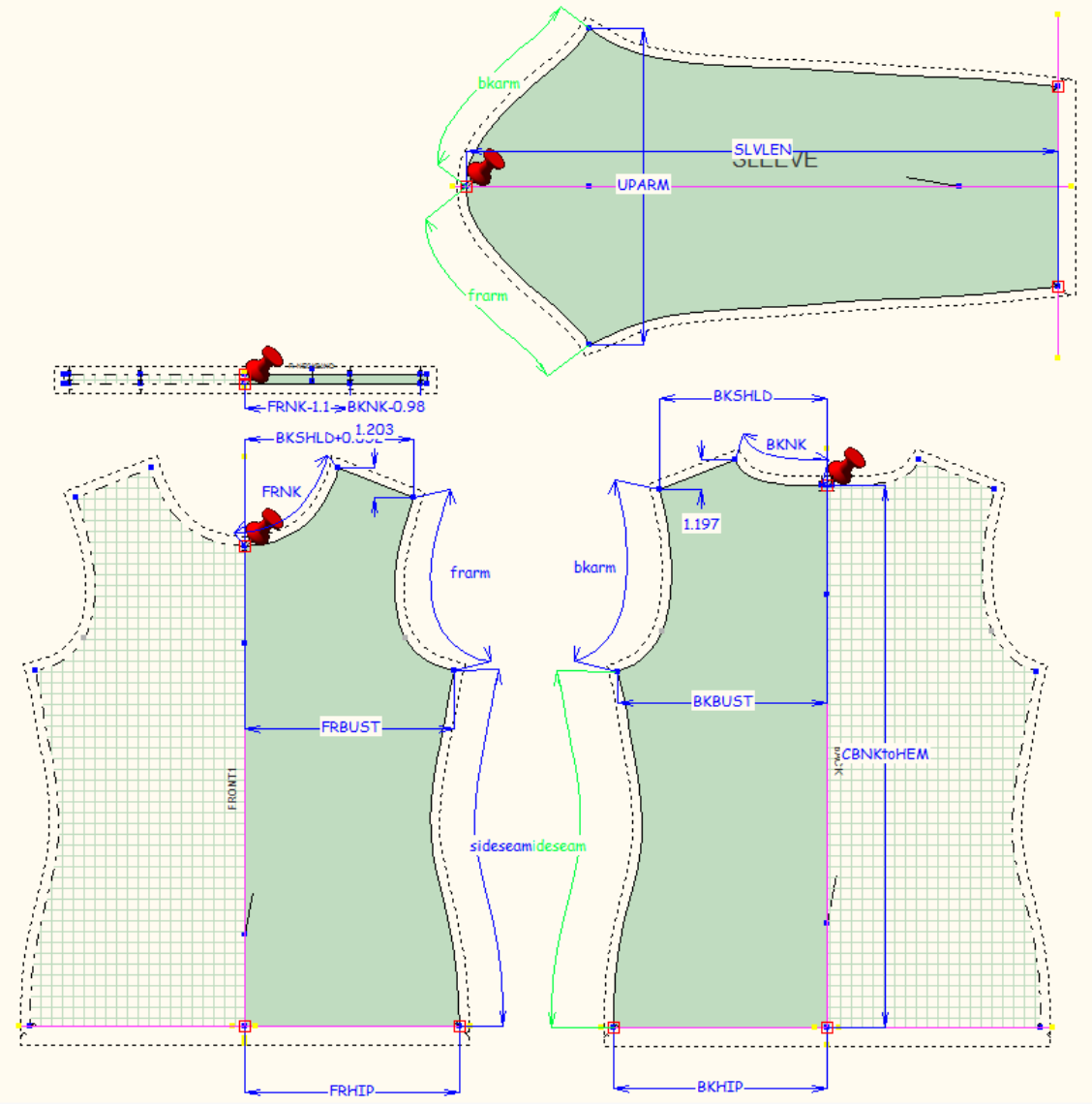

$\begin{array}{lrl}\text { BUST } & 37 & (2 *(\text { FRBUST+BKBUST }))+3 \\ \text { HIP } & 38 & (2 *(\text { FRHIP+BKHIP }))+3.25 \\ \text { SHOULDER } & 14.5 & \text { BKSHLD*2+.888 } \\ \text { BICEP } & 12.001 & \text { UPARM-.797 } \\ \text { NECK } & 15 & \text { ((FRNK+BKNK)*2)-3.425 } \\ \text { LENGTH } & 22 & \text { CBNKtoHEM } \\ \text { SLEEVE_LONG } & 24 & \text { SLVLEN }\end{array}$

Figure 5. Example of Parametric Modelling of a T- Shirt. Optitex Modulate used for Parametric Modeling.

\section{Conclusion}

Research is required to define the measurements collected from whole body scanners. It is product and market dependent.

Pattern CAD technology from Optitex Ltd. offers Modulate to set up a direct relationship from the scanned measurements to the pattern.

The customer is the most important part of the equation. Managing their expectations on what you are delivering is vital to the success of the services and product you are offering

This paper and presentation does not address the issue of mass customization. Issues related to offering customer preferences for function, fabric and color were not addressed. 